\title{
Risk-Return Trade-off and Volatility Characteristics in the Indian Stock Market
}

\author{
Manickam Tamilselvan ${ }^{1}$, Srinivasan Palamalai ${ }^{2}$, Magesh Kumar ${ }^{2}$, \\ Jayakumar Aswathaman ${ }^{1}$, Manjula Veerabhadrappa ${ }^{1}$ \\ ${ }^{1}$ Faculty of Business Studies Department, University of Technology \& Applied Sciences, \\ Ibri - Sultanate of Oman, \\ ${ }^{2}$ School of Management, Presidency University, Bangalore, Karnataka, India
}

\begin{abstract}
The study examines the volatility characteristics of Indian stock markets and their tradeoff between the risk and return. It finds a positive but insignificant association between the risk and returns during the subsample (the pre-COVID and COVID pandemic outbreak) and whole sample periods. The study also shows that the weak form of Indian stock markets is not sustainable. Consistent with the GARCH literature, persistent and asymmetric effects are evidenced, and the magnitude of the negative shocks has a larger immediate impact than the positive shocks. These results would help measure the volatility in the Indian stock markets and provide investors and regulators with necessary information about the market efficiency, persistency (long-memory process) and asymmetric effects.
\end{abstract}

Keywords - hybrid GARCH-Mean type models, asymmetric volatility, volatility clustering, risk-return trade-off, weak-form efficiency.

\section{Introduction}

Investors consider the risk-return tradeoff as an essential element of investment decisions while evaluating their portfolios as a whole. According to the economic theory of portfolio [1], investors who

DOI: $10.18421 /$ TEM111-38

https://doi.org/10.18421/TEM111-38

Corresponding author: Srinivasan Palamalai, School of Management, Presidency University, Bangalore, Karnataka, India.

Email: srinivasaneco@gmail.com

Received: 13 December 2021.

Revised: 05 February 2022.

Accepted: 10 February 2022.

Published: 28 February 2022.

(cc)BY-NC-ND@ 2022 Manickam Tamilselvan et al; published by UIKTEN. This work is licensed under the Creative Commons Attribution-NonCommercial-NoDerivs 4.0 License.

The article is published with Open Access at https://www.temjournal.com/ seek a higher return on their portfolio have to bear more risk. The Capital Asset Pricing Model (CAPM) and the Arbitrage Pricing Model (APT) proposed that the expected returns on stocks would be positively affected by the volatility of the market. However, the Inter-temporal Capital Asset Pricing (ICAPM) theory suggests an unstable and negative relation between the risk-return trade-off [2].

The risk factor is represented by the volatility dynamics of the equity markets as it is strongly linked to market uncertainty [3]. A higher level of volatility denotes that the price of the asset will fluctuate significantly, and lesser volatility suggests it change at a consistent rate over time [4]. A larger volatility phase usually follows the larger volatility phase, and a minor volatility phase follows the low volatility phase in an asset class, which is referred to as volatility clustering [5]. The behavior of volatility clustering is very dynamic as the volatility changes over time, and it shows a tendency of persistence, suggesting that the returns take considerable time to revert to their previous level. In other words, the volatility shock fades over time and eventually reverts to its equilibrium position. This phenomenon is known as mean reversion, and as a result, the response to news arrival is asymmetrical. Asymmetric effects explain the relation between the current variance and previous information shocks. The negative shocks raise volatility by a large proportion compared with equal-sized positive disturbances [6]. This asymmetric impact is often referred to as the leverage effect. According to Black [7] and Christie [8], the leverage effect occurs due to a fall in the stock prices that reduces the equity value of the firms. Since the debt remains constant, the financial leverage increases and raises the firms' riskiness, hence the volatility of futures returns.

Since the asymmetric effect describes the association between volatility and changes in the stock price, the investors have to determine whether the time series is symmetrical or asymmetrical in its response to positive and negative news. Therefore, a study on the stock market's risk-return trade-off and volatility characteristics assume greater significance among the market participants, arbitrageurs, regulators, and financial practitioners. 


\section{Review of Literature}

It is well known that volatility has the properties of leptokurtic distribution due to outliers in the returns series, clustering and persistence effects due to its time-varying nature. Existing studies show that stock returns from developing economies have unique volatility attributes from developed markets [9], [10], [11]. Furthermore, in contrast to established markets, volatility in developing markets is primarily influenced by local news or events and sudden shifts [12]. In accordance with the finance and economics applications, the most widely used models for modelling volatility is the Auto Regressive Conditionally Heteroscedastic (ARCH). The GARCH-type models successfully accounted for crucial characteristics of returns series such as volatility clustering, persistence, and asymmetric effects. Lim and Sek [13] compared the performance of symmetric and asymmetric GARCH (Generalized Autoregressive Conditional Heteroscedasticity) models on the stock market in Malaysia for before, during and post-crisis period of 1997. The results signify distinct performances of symmetric and asymmetric GARCH models in various periods. For the pre- and post-crisis periods, the symmetric GARCH model outperforms the asymmetric GARCH model, and the asymmetric GARCH model is preferred during the crisis period. The findings revealed that exchange rates and crude oil prices strongly influenced Malaysian stock market volatility during the pre-and post-crisis periods. However, there was no such impact during the crisis period.

In a European country study, Ugurlu et al. [14] employed GARCH, GJR-GARCH and ExponentialGARCH models to measure volatility in the countries such as Bulgaria, Czech Republic, Hungary, Poland and Turkey. The GARCH effect was detected except in the Bulgarian market. Nevertheless, the volatility shocks are persistent in all four markets, and the Polish stock market has a long memory among all the markets. Furthermore, according to the study, bad news raises volatility and markets had a leveraging effect on returns. Earlier, Gabriel [15] applied GARCH models (GARCH, EGARCH, TGARCH, PGARCH, IGARCH) for the Romanian stock market and highlighted that TGARCH is the fittest model in forecasting the volatility. The outcomes have significant inferences for measuring Value-at-Risk (VaR) and managing various risks.

Coffie [16] examined the risk premium and persistence effect in the Southern and East African stock markets using GARCH and GARCH-in-Mean (GARCH-M) models. The study reveals that volatility decay differs significantly across the markets. The study suggests that investors look beyond the mean-variance analysis by observing more volatility, correlation, skewness, and kurtosis results. Besides, Tripathy and Gil-Alana [17] studied the volatility features of the Indian stock markets and showed the presence of asymmetric effect during the pre- and global financial crisis periods. Further, the earlier findings by Srinivasan and Kalaivani [18] supported the presence of ARCH and GARCH effects in the Indian stock market returns. The authors found that the asymmetric GARCH models reveal the leverage effect. Based on out of sample forecast and error measurements, Vasudevan and Vetrivel [19] forecasted the volatility of the Indian stock market and showed that the EGARCH (1 1) model is more appropriate. Dangi [20] analyzed the risk-return relationship using GARCH models for the banking indices and confirmed the occurrence of persistent volatility and asymmetric effect, and no sign of risk-return relationship. Using GARCH family models, Marobhe and Pastory [21] found that the magnitude of shocks in volatility is stronger for positive news than bad news in the Tanzania stock market. The PGARCH technique was more effective in projecting stock returns based on the error measurement. Also, Herbert et al. [22] found volatility clustering and significant leverage effects in the Nigerian stock market using GARCH models. The results recommend suitable policy measures to check the volatility patterns and control negative shocks that increase market uncertainty.

Using the GARCH model, Chaudhary et al. [23] studied the impact of COVID-19 on the return and volatility of emerging stock market indices. As a result of the COVID-19 spread, the volatility has increased. In addition, the results illustrate a mean reversion process on all markets over a specified period. Furthermore, Duttilo et al. [24] investigated the impact of the first and second waves of COVID19 outbreaks on European stock market volatility. The risk premium and leverage effect are evaluated using a threshold GARCH (1 1)-in-Mean model. The findings show that the Euro Zone stock markets reacted negatively to the COVID-19. The first wave had a significant impact on volatility in Eurozone countries, while the second wave had a large impact on the Belgian market. The impact of the COVID-19 pandemic on stock market volatility in G7 countries was explored by Yousef [25]. According to the findings, the COVID-19 epidemic caused high stock market volatility and had a positive and considerable leverage effect on the German, French, and Italian stock markets.

Bora and Basitha [26] found that Indian stock market returns were higher during the pre-COVID-19 period than during the crisis period. Adverse shocks had a significant impact on volatility than positive shocks. The epidemic of COVID-19 has no 
substantial impact on volatility. According to Zhang et al. [27], the TGARCH model is more robust in assessing stock market volatility in China and the most developed stock markets during the COVID-19 shocks. The leverage effect was evident. A research study by Dwarika et al. [28] revealed that the South African market has a high level of volatility persistence.

From a chronological review of the related literature, it was noted that the significant asymmetric effect in the Indian stock markets is evidenced. By taking into account the asymmetric effects in the returns series, the present study uncovers a clear association between the risk and return trade-off for the three intervals, i.e. preCOVID period, during COVID period and the whole sample period. Moreover, the study employed a hybrid class of ARIMA-GARCH type models to examine volatility persistence and asymmetric effects to discriminate the impact of positive and negative news for all the sample periods. The findings of this study are the need of the hour that assist regulators and practitioners to ensure better market integrity and maintaining efficient markets in the light of varying stock market dynamics during COVID-19. With this in mind, this study proposes three research questions: (i) Is there any significant relationship between the risk and returns in the Indian stock markets? (ii) Is there any significant persistence of shocks to volatility in the Indian stock markets? and (iii) Does stock market returns display a significant level of asymmetric volatility effect?

\section{Methodology}

\subsection{Dataset}

We use secondary daily closing price data of the BSE Sensex from Bombay Stock Exchange (BSE) and S\&P CNX Nifty from National Stock Exchange (NSE) from $29^{\text {th }}$ January 2018 to $20^{\text {th }}$ July 2021 , consisting of 859 observations. We classify the whole sample period into the pre-COVID phase from $29^{\text {th }}$ January 2018 to $29^{\text {th }}$ January 2020 and the COVID pandemic outbreak phase - from $30^{\text {th }}$ January 2020 to $20^{\text {th }}$ July 2021. The dataset is obtained from the Bloomberg and Centre for Monitoring Indian Economy (CMIE) Prowess database. The stock market returns have been computed using the formula: $\mathrm{R}_{t}=\operatorname{Ln}\left(\mathrm{P}_{t} / \mathrm{P}_{\mathrm{t}-1}\right), \mathrm{P}_{\mathrm{t}}$ is the price of the present period, and $\mathrm{P}_{\mathrm{t}-1}$ is the price of the preceding period.

\subsection{Generalized Autoregressive Conditional Heteroscedasticity (GARCH) Model}

The ARIMA-GARCH-Mean ( $p, q)$ process is specified as:

Mean Equation: $\mathrm{R}_{\mathrm{t}}=\mathrm{a}_{0}+\mathrm{a}_{1} \mathrm{R}_{\mathrm{t}-1}+\mathrm{b}_{1} \varepsilon_{\mathrm{t}-1}+\lambda \sigma^{2} \mathrm{t}+\varepsilon_{\mathrm{t}}$

Variance Equation: $h_{t}=\omega_{1}+\sum_{i=1}^{p} \alpha_{1} \varepsilon_{t-i}^{2}+\sum_{j=1}^{q} \beta_{1} h_{t-j}$

where $a_{1}$ and $b_{1}$ denote the AR and MA terms, respectively. The ARMA orders are identified based on the significant $\mathrm{AR}$ and MA coefficients and lowest AIC (Akaike Information Criteria) and SIC (Schwarz Information Criteria) statistics. $\lambda$ is the risk premium parameter. If $\lambda$ is positive and significant, it implies that the return increases with greater risk. Under variance equation, $\alpha_{\mathrm{i}}$ and $\beta_{1}$ represents $\mathrm{ARCH}$ and GARCH parameter, respectively. Moreover, the significant ARCH and GARCH processes are selected based on AIC and SIC.

\subsection{Exponential Generalized Autoregressive Conditional Heteroscedasticity (EGARCH) Model}

The ARIMA-EGARCH-Mean ( $p, q)$ process is specified as:

Mean Equation: $\mathrm{R}_{\mathrm{t}}=\mathrm{a}_{0}+\mathrm{a}_{1} \mathrm{R}_{\mathrm{t}-1}+\mathrm{b}_{1} \varepsilon_{\mathrm{t}-1}+\lambda \sigma^{2} \mathrm{t}+\varepsilon_{\mathrm{t}}$

Variance Equation: $\ln \left(\sigma_{\mathrm{t}}^{2}\right)=\omega_{1}{ }^{+} \beta_{1} \ln \left(\sigma_{\mathrm{t}-1}^{2}\right)+\alpha_{1}$ $\left|\frac{\varepsilon \mathrm{t}-1}{\sigma_{\mathrm{t}-1}}\right|+\gamma_{1} \frac{\varepsilon \mathrm{t}-1}{\sigma_{\mathrm{t}-1}}$

Since the logarithmic conditional variance is modelled in the above model, no non-negativity parameter limitation is required. It is a variation of the GARCH model in which conditional variance affects both positive and negative returns differently. The parameter $\gamma 1$ captures the asymmetric effect. If there is a leverage effect, a positive shock has a smaller impact on conditional variance than a negative shock. The relevant AR term, MA term, ARCH and GARCH processes are selected based on AIC and SIC, similar to the ARIMA-GARCH-M model. 


\section{Results}

Table 1 shows the statistical properties of the return series. Average returns in Indian equity markets are high during the COVID19 phase. The returns and standard deviation of BSE and NSE during the pandemic outbreak phase of COVID19 are relatively higher than the pre-COVID phase. Skewness values are negative during the COVID period, suggesting that investors often expect small gains and large losses. In contrast, the positive values during the pre-COVID phase show the probability of obtaining large gains that can cover all the frequent small losses. The kurtosis values are greater than three, suggesting that the return series has stronger tails than a normal distribution. Moreover, the Jarque-Bera statistics validate the non-normality of the returns for all the sample periods. Thus, the results from the summary statistics showed that the NSE and BSE market returns followed an asymmetric distribution.

Table 1. Descriptive Statistics

\begin{tabular}{lcccccc}
\hline \multicolumn{1}{c}{ Statistics } & \multicolumn{3}{c}{ BSE Returns } & \multicolumn{3}{c}{ NSE Returns } \\
\cline { 2 - 7 } & $\begin{array}{c}\text { Pre-COVID } \\
\text { Period }\end{array}$ & COVID Period & $\begin{array}{c}\text { Full Sample } \\
\text { Period }\end{array}$ & $\begin{array}{c}\text { Pre-COVID } \\
\text { Period }\end{array}$ & $\begin{array}{c}\text { COVID Period Full Sample } \\
\text { Period }\end{array}$ \\
\hline Mean (\%) & 0.0271 & 0.0665 & 0.0439 & 0.0185 & 0.0665 & 0.0411 \\
Maximum (\%) & 5.1859 & 8.5947 & 8.5947 & 5.1825 & 8.5947 & 8.4003 \\
Minimum (\%) & -2.3669 & -14.101 & -14.101 & -2.7044 & -14.101 & -13.903 \\
Std. Dev. & 0.0083 & 0.0181 & 0.0134 & 0.0084 & 0.0181 & 0.0132 \\
Skewness & 0.5025 & -1.6555 & -1.6400 & 0.4667 & -1.6555 & -1.6745 \\
Kurtosis & 6.3902 & 17.113 & 24.739 & 6.2987 & 17.113 & 24.365 \\
Jarque-Bera & $256.84^{*}$ & $3204.9^{*}$ & $17300.7 *$ & $241.42^{*}$ & $3204.9 *$ & $16739.9 *$ \\
& $(0.0000)$ & $(0.0000)$ & $(0.0000)$ & $(0.0000)$ & $(0.0000)$ & $(0.0000)$ \\
Observations & 493 & 366 & 859 & 493 & 366 & 859 \\
\hline
\end{tabular}

*- indicates the significance at one percent level. ( ) - probability values are in the parenthesis.

Table 2. Autocorrelation and Heteroscedasticity test results

\begin{tabular}{ccccccc}
\hline \multirow{2}{*}{$\begin{array}{c}\text { Test } \\
\text { statistics }\end{array}$} & $\begin{array}{c}\text { Pre-COVID } \\
\text { Period }\end{array}$ & $\begin{array}{c}\text { COVID } \\
\text { Period }\end{array}$ & $\begin{array}{c}\text { Full Sample } \\
\text { Period }\end{array}$ & $\begin{array}{c}\text { Pre-COVID } \\
\text { Period }\end{array}$ & $\begin{array}{c}\text { COVID } \\
\text { Period }\end{array}$ & $\begin{array}{c}\text { Full Sample } \\
\text { Period }\end{array}$ \\
\hline \multirow{2}{*}{ Q[12] } & $26.319^{*}$ & $70.172^{*}$ & $95.019^{*}$ & $26.831^{*}$ & $78.842^{*}$ & $105.27^{*}$ \\
& $(0.010)$ & $(0.000)$ & $(0.000)$ & $(0.008)$ & $(0.000)$ & $(0.000)$ \\
$\mathrm{Q}^{2}[12]$ & $33.888^{*}$ & $248.27^{*}$ & $630.79^{*}$ & $37.858^{*}$ & $234.98^{*}$ & $594.22^{*}$ \\
ARCH- & $(0.001)$ & $(0.000)$ & $(0.000)$ & $(0.000)$ & $(0.000)$ & $(0.000)$ \\
LM [1] & $22.132^{*}$ & $10.132^{*}$ & $30.425^{*}$ & $24.829^{*}$ & $9.7949^{*}$ & $29.533^{*}$ \\
\hline
\end{tabular}

*- indicates the significance at one percent level. ( ) - probability values are in the parenthesis. [ ] - values in the squared brackets indicate lag-length.

Table 2 depicts the test results for autocorrelation and heteroscedasticity. Since the p-values of both the Ljung-Box test for residuals and squared residuals are less than a five percent significance level, the null of the existence of autocorrelation and heteroscedasticity is rejected respectively. Besides, the ARCH-LM test confirms the existence of heteroscedasticity within the BSE and NSE return series. Thus, it was concluded that autocorrelation and heteroscedasticity exist in the return series, which supported GARCHtype approaches.

In order to assess the stationarity condition of the return series, the Augmented Dickey-Fuller (ADF) test results are shown in Table 3. The results reveal that the return series is stationarity during all the sample periods. This contradicts the random-walk hypothesis. In other words, the ADF test confirms that the Indian markets are weak-form inefficient markets, that the returns are predictable using historical information.

We employed the ARIMA-GARCH-Mean and ARIMA-EGARCH-Mean models to investigate volatility features and risk-return relation in the Indian stock markets. First, we estimated the various ARIMA models for the BSE and NSE returns to identify the parsimonious AR and MA terms using SIC and AIC. For BSE returns, the AIC and SIC suggest a more parsimonious model with $\mathrm{AR}=5$ and $\mathrm{MA}=5$ for the pre-COVID and whole sample periods, and $\mathrm{AR}=6$ and $\mathrm{MA}=6$ for the COVID 
Table 3. ADF test results

\begin{tabular}{ccccccc}
\hline \multirow{2}{*}{ Parameter } & \multicolumn{3}{c}{ BSE Returns } & \multicolumn{3}{c}{ NSE Returns } \\
\cline { 2 - 7 } & $\begin{array}{c}\text { Pre-COVID } \\
\text { Period }\end{array}$ & $\begin{array}{c}\text { COVID } \\
\text { Period }\end{array}$ & \multirow{2}{*}{ Full Sample Period } & $\begin{array}{c}\text { Full Sample } \\
\text { Period }\end{array}$ & $\begin{array}{c}\text { Pre-COVID } \\
\text { Period }\end{array}$ & $\begin{array}{c}\text { COVID } \\
\text { Period }\end{array}$ \\
\hline Intercept & $-21.2758^{*}$ & $-5.89635^{*}$ & $-10.107^{*}$ & $-9.96854^{*}$ & $-21.1509^{*}$ & $-5.73675^{*}$ \\
& $(0.0000)$ & $(0.0000)$ & $(0.0000)$ & $(0.0000)$ & $(0.0000)$ & $(0.0000)$ \\
Intercept \& Trend & $-21.2797^{*}$ & $-5.97212^{*}$ & $-10.123^{*}$ & $-9.99463^{*}$ & $-21.1549^{*}$ & $-5.81998^{*}$ \\
& $(0.0000)$ & $(0.0000)$ & $(0.0000)$ & $(0.0000)$ & $(0.0000)$ & $(0.0000)$ \\
\hline
\end{tabular}

*- indicates the significance at one percent level. ( ) - probability values are in the parenthesis.

Table 4. Identification of parsimonious ARIMA-GARCH-M type models

\begin{tabular}{cccc}
\hline & & BSE Returns \\
Period & ARIMA Process & $\begin{array}{c}\text { GARCH (p q) } \\
\text { Process }\end{array}$ & $\begin{array}{c}\text { Hybrid ARIMA-GARCH-Mean } \\
\text { Model }\end{array}$ \\
\hline $\begin{array}{c}\text { Pre-COVID } \\
\text { COVID }\end{array}$ & ARIMA (5 5) & GARCH-M (2 1) & ARIMA (5 5)-GARCH-M (2 1) \\
Full Sample & ARIMA (6 6) & GARCH-M (1 1) & ARIMA (6 6)-GARCH-M (1 1) \\
\hline & ARIMA (5 5) & GARCH-M (5 5) & ARIMA (5 5)-GARCH-M (5 5) \\
\hline \multicolumn{3}{c}{ NSE Returns } \\
Period & ARIMA Process & GARCH (p q) & Hybrid ARIMA-GARCH-Mean \\
Pre-COVID & ARIMA (5 5) & GARCH-M (2 1) & ARIMA (5 5)-GARCH-M (2 1) \\
COVID & ARIMA (5 5) & GARCH-M (2 1) & ARIMA (5 5)-GARCH-M (2 1) \\
Full Sample & ARIMA (5 5) & GARCH-M (1 5) & ARIMA (5 5)-GARCH-M (1 5) \\
\hline The appropriate (statistically significant) AR term, MA term and ARCH (p) and GARCH (q) terms for the \\
parsimonious ARIMA-GARCH-M type models are selected based on SIC and AIC.
\end{tabular}

sample period. For NSE returns, the $\mathrm{AR}=5$ and $\mathrm{MA}=5$ is found to be appropriate for all the sample periods. Second, to determine the appropriate variance equations, we estimate the ARIMAGARCH (p q) model with various values of $p$ and $q$. The AIC and SIC suggest a more parsimonious model with $\mathrm{p}=2$ and $\mathrm{q}=1$ for the pre-COVID phase for BSE returns. Further, it is found that $\mathrm{p}=1$ and $\mathrm{q}$ $=1$ for the COVID phase and $\mathrm{p}=5$ and $\mathrm{q}=5$ for the whole sample period. For NSE returns, it is found that $\mathrm{p}=2$ and $\mathrm{q}=1$ for the pre-COVID and COVID phases and $p=1$ and $q=5$ for the whole sample period. Accordingly, we determined the appropriate model specifications for the BSE and NSE returns, as depicted in Table 4.

The result of hybrid ARIMA-GARCH-M type models for the BSE is shown in Table 5, revealing that the AR and MA parameters in all the estimations are statistically significant. For the pre-COVID, COVID pandemic outbreak and whole sample periods, the sum of ARCH $(\alpha)$ and GARCH $(\beta)$ effects in the ARIMA-GARCH-Mean estimations are nearer to one, which means that larger variance is generally trailed by larger volatility, and the lesser volatility generally trails low variance. This confirms that volatility clustering is observed in the BSE returns series. Furthermore, the GARCH coefficients in the variance equations are significantly higher than ARCH coefficients, showing that the market has a longer memory and volatility is more responsive to lagged conditional variance than to new shocks. This suggests that the volatility is persistent during the sample periods. The persistent and long-memory volatility would result in a price mismatch in the Indian stock markets. Thus there exists an arbitrage opportunity for investors to capitalize.

According to the AIC and SIC criteria, the ARIMA-EGARCH-M models were more efficient than the ARIMA-GARCH-M models. The asymmetric parameters $(\gamma \mathrm{s})$ substantiate the existence of significant leverage effects signifying that the variance increases due to negative news than the positive news, and hence the asymmetric GARCH models are more efficient than GARCH models. According to ARIMA-EGARCH-M models, the risk premium coefficient $(\lambda)$ in the mean equations are positive but statistically insignificant for the sample periods, suggesting that the increased risk did not increase the returns in the BSE market. This demonstrates that investors' expected returns are unaffected by the risk they are taking, and the risk has no bearing on the magnitude of their projected return, implying that investors are risk-averse. 
Table 5. Hybrid GARCH-type models for BSE returns

\begin{tabular}{|c|c|c|c|c|c|c|}
\hline \multicolumn{7}{|c|}{ Panel A: Pre-COVID-19 Period } \\
\hline \multicolumn{7}{|c|}{$\begin{array}{c}\text { Mean Equation } \\
\end{array}$} \\
\hline Hybrid Model & $\mu$ & $\mathrm{AR}$ & $\mathrm{MA}$ & $\lambda$ & & \\
\hline ARIMA (5 5)-GARCH- & 0.0006 & $0.5027 * *$ & $-0.5299^{*}$ & 4.1573 & & \\
\hline $\mathrm{M}(21)$ & $(0.7660)$ & $(2.4768)$ & $(-2.6552)$ & $(0.3218)$ & & \\
\hline ARIMA (5 5)- & $0.0015 * *$ & $0.4385 * * *$ & $-0.4598 * * *$ & 16.676 & & \\
\hline EGARCH-M (2 1) & $(2.0513)$ & $(1.7993)$ & $(-1.8995)$ & $(1.3313)$ & & \\
\hline \multicolumn{7}{|c|}{ Variance Equation } \\
\hline Hybrid Model & $\mu$ & $\alpha$ & $\beta$ & $\gamma_{1}$ & $\mathrm{AIC}$ & $\begin{array}{c}\text { ARCH-LM } \\
\text { Stat. }\end{array}$ \\
\hline ARIMA (5 5)-GARCH- & $3.47 \mathrm{E}-06$ & $-0.1780 * *$ & $0.8541^{*}$ & & & 0.07689 \\
\hline $\mathrm{M}(21)$ & $(1.3283)$ & $(-2.3573)$ & $(10.514)$ & - & -6.81919 & {$[0.7816]$} \\
\hline ARIMA (5 5)- & $-13.410 *$ & $0.4812 *$ & $-0.2956 * * *$ & $-0.2429 *$ & & 0.38551 \\
\hline EGARCH-M (2 1) & $(-8.0104)$ & $(3.7557)$ & $(-1.7604)$ & $(-5.0718)$ & $-6.8583 /$ & {$[0.5347]$} \\
\hline \multicolumn{7}{|c|}{ Panel B: COVID-19 Period } \\
\hline \multicolumn{7}{|c|}{ Mean Equation } \\
\hline Hybrid Model & $\mu$ & AR & MA & $\lambda$ & & \\
\hline ARIMA(6 6)-GARCH- & $0.0013 * *$ & $0.5296^{*}$ & $-0.5902 *$ & 3.9395 & & \\
\hline$M(11)$ & $(2.1670)$ & $(4.2626)$ & $(-5.2124)$ & $(1.3421)$ & & \\
\hline ARIMA (6 6)- & $0.0013 * *$ & $0.4829 * *$ & $-0.5182 * *$ & 3.3226 & & \\
\hline EGARCH-M $(1,1)$ & $(2.0572)$ & $(2.2932)$ & $(-2.5561)$ & $(1.0839)$ & & \\
\hline \multicolumn{7}{|c|}{ Variance Equation } \\
\hline Hybrid Model & $\mu$ & $\alpha$ & $\beta$ & $\gamma_{1}$ & AIC & $\begin{array}{c}\text { ARCH-LM } \\
\text { Stat. }\end{array}$ \\
\hline ARIMA(6 6)- & $5.74 \mathrm{E}-06$ & $0.1408 *$ & $0.8373 *$ & & 587201 & 1.2182 \\
\hline GARCH-M (1 1) & $(1.5540)$ & $(3.1589)$ & $(17.277)$ & - & $-5.8 / 201$ & {$[0.2697]$} \\
\hline ARIMA (6 6) & $-0.3979 *$ & $0.1578 * *$ & $0.9692 *$ & $-0.1566^{*}$ & & 0.7901 \\
\hline EGARCH-M (1 1) & $(-2.9389)$ & $(2.1821)$ & $(70.04)$ & $(-3.2786)$ & -5.91058 & {$[0.3741]$} \\
\hline \multicolumn{7}{|c|}{ Panel C: Full Sample Period } \\
\hline \multicolumn{7}{|c|}{ Mean Equation } \\
\hline Hybrid Model & $\mu$ & $\mathrm{AR}$ & MA & $\lambda$ & $\mathrm{D}_{\text {avid }}$ & \\
\hline ARIMA (5 5) & -0.0004 & $0.4771 * * *$ & $-0.4679 * * *$ & $0.1649 * * *$ & 0.0006 & \\
\hline GARCH-M (5 5) & $(-0.5337)$ & $(1.7904)$ & $(-1.7368)$ & $(1.6519)$ & $(1.0872)$ & \\
\hline ARIMA (5 5 ) & -0.0004 & $0.7512 *$ & $-0.7053^{*}$ & 4.8117 & $0.0015^{*}$ & \\
\hline EGARCH-M (5 5) & $(-0.9072)$ & $(5.8135)$ & $(-4.9644)$ & $(1.1571)$ & $(3.0982)$ & \\
\hline \multicolumn{7}{|c|}{ Variance Equation } \\
\hline Hybrid Model & $\mu$ & $\alpha$ & $\beta$ & $\gamma_{1}$ & AIC & $\begin{array}{c}\text { ARCH-LM } \\
\text { Stat. }\end{array}$ \\
\hline ARIMA (5 5) & $1.10 \mathrm{E}-05^{*}$ & $0.1200^{*}$ & $0.7458 *$ & & & 0.3671 \\
\hline GARCH-M (5 5) & $(6.0847)$ & $(9.6878)$ & $(30.448)$ & - & $-6.3 / 2 / 0$ & {$[0.5446]$} \\
\hline ARIMA(5 5) & $-0.3819 *$ & $-0.1290 * *$ & $-0.4084 *$ & $-0.1606^{*}$ & -642502 & 0.0622 \\
\hline EGARCH-M (5 5) & $(-3.6006)$ & $(-2.2417)$ & $(-3.2736)$ & $(-4.5212)$ & -6.42502 & [0.8029] \\
\hline
\end{tabular}

Table 6. Hybrid GARCH-type models for NSE returns

\begin{tabular}{|c|c|c|c|c|c|c|}
\hline \multicolumn{7}{|c|}{ Panel A: Pre-COVID-19 Period } \\
\hline \multicolumn{7}{|c|}{ Mean Equation } \\
\hline Hybrid Model & $\mu$ & $\mathrm{AR}$ & MA & $\lambda$ & & \\
\hline ARIMA (5 5) & 0.0004 & $0.4946^{* *}$ & $-0.5129 * *$ & 6.0373 & & \\
\hline GARCH-M (2 1) & $(0.5381)$ & $(2.0429)$ & $(-2.1416)$ & $(0.4876)$ & & \\
\hline ARIMA (5 5) & $1.10 \mathrm{E}-05$ & $0.5378 *$ & $-0.5509 *$ & 0.0617 & & \\
\hline EGARCH-M (2 1) & $(0.0090)$ & $(3.0688)$ & $(-3.1481)$ & $(0.3667)$ & & \\
\hline \multicolumn{7}{|c|}{ Variance Equation } \\
\hline Hybrid Model & $\mu$ & $\alpha$ & $\beta$ & $\gamma_{1}$ & AIC & $\begin{array}{c}\text { ARCH-LM } \\
\text { Stat. }\end{array}$ \\
\hline ARIMA (5 5) & $3.95 \mathrm{E}-06$ & $-0.1796 * *$ & $0.8408 * *$ & & 670812 & 0.0713 \\
\hline GARCH-M (2 1) & $(1.3546)$ & $(-2.2943)$ & $(9.6490)$ & - & -6.19813 & {$[0.7894]$} \\
\hline ARIMA (5 5) & $-0.6928 * *$ & $-0.2165 * *$ & $0.9363^{*}$ & $-0.1836^{*}$ & -6.80819 & 0.03122 \\
\hline
\end{tabular}




\begin{tabular}{|c|c|c|c|c|c|c|}
\hline EGARCH-M (2 1) & $(-2.3539)$ & $(-2.2171)$ & $(33.205)$ & $(-4.7330)$ & & {$[0.8597]$} \\
\hline \multicolumn{7}{|c|}{ Panel B: COVID-19 Period } \\
\hline \multicolumn{7}{|c|}{ Mean Equation } \\
\hline Hybrid Model & $\mu$ & $\mathrm{AR}$ & MA & $\lambda$ & & \\
\hline ARIMA (5 5) & 0.0001 & $0.7970^{*}$ & $-0.7328 *$ & 5.1983 & & \\
\hline GARCH-M (2 1) & $(0.2008)$ & $(20.380)$ & $(-17.674)$ & $(1.3532)$ & & \\
\hline ARIMA (5 5) & $3.5 \mathrm{E}-05$ & $-0.8763 *$ & $0.9662 *$ & 6.8282 & & \\
\hline EGARCH-M (2 1) & $(0.0420)$ & $(-27.420)$ & $(42.007)$ & $(1.5209)$ & & \\
\hline \multicolumn{7}{|c|}{ Variance Equation } \\
\hline Hybrid Model & $\mu$ & $\alpha$ & $\beta$ & $\gamma_{1}$ & AIC & $\begin{array}{l}\text { ARCH-LM } \\
\text { Stat. }\end{array}$ \\
\hline ARIMA (5 5) & $5.71 \mathrm{E} 06^{*}$ & $0.1512^{*}$ & $0.6212 *$ & & & 0.5368 \\
\hline GARCH-M (2 1) & $(2.7459)$ & $(5.0939)$ & $(7.8113)$ & - & -5.83344 & {$[0.4638]$} \\
\hline ARIMA (5 5) & $-0.2001^{*}$ & $0.0472 * * *$ & $0.5143 * *$ & $-0.0602 *$ & & 0.0006 \\
\hline EGARCH-M (2 1) & $(-2.7959)$ & $(1.7229)$ & $(2.2374)$ & $(-2.8975)$ & -5.91285 & {$[0.9801]$} \\
\hline \multicolumn{7}{|c|}{ Panel C: Full Sample Period } \\
\hline \multicolumn{7}{|c|}{ Mean Equation } \\
\hline Hybrid Model & $\mu$ & $\mathrm{AR}$ & MA & $\lambda$ & $\mathrm{D}_{\text {avid }}$ & \\
\hline ARIMA (5 5) & 0.0001 & $0.5348 * *$ & $-0.5083 * *$ & $8.5822 *$ & $0.0011 * * *$ & \\
\hline GARCH-M (1 5) & $(0.3506)$ & $(2.3487)$ & $(-2.1889)$ & $(2.6817)$ & $(1.8735)$ & \\
\hline ARIMA (5 5) & -0.0006 & $0.5860^{*}$ & $-0.5447 * *$ & 6.1605 & $0.0014 *$ & \\
\hline EGARCH-M (1 5) & $(-1.5188)$ & $(2.7131)$ & $(-2.4206)$ & $(1.5965)$ & $(2.7753)$ & \\
\hline \multicolumn{7}{|c|}{ Variance Equation } \\
\hline Hybrid Model & $\mu$ & $\alpha$ & $\beta$ & $\gamma_{1}$ & AIC & $\begin{array}{l}\text { ARCH-LM } \\
\text { Stat. }\end{array}$ \\
\hline $\begin{array}{l}\text { ARIMA (5 5) GARCH-M (1 } \\
5)\end{array}$ & $\begin{array}{c}6.62 \mathrm{E}-06^{*} \\
(3.1280)\end{array}$ & $\begin{array}{l}0.1543^{*} \\
(4.7204)\end{array}$ & $\begin{array}{l}0.5477^{*} \\
(4.7039)\end{array}$ & - & -6.37780 & $\begin{array}{c}0.00019 \\
{[0.9889]}\end{array}$ \\
\hline $\begin{array}{l}\text { ARIMA (5 5) EGARCH-M (1 } \\
\text { 5) }\end{array}$ & $\begin{array}{l}-0.3432 * \\
(-4.9642)\end{array}$ & $\begin{array}{l}0.1082 * \\
(3.4386)\end{array}$ & $\begin{array}{l}0.4754^{*} \\
(3.6462)\end{array}$ & $\begin{array}{l}-0.1144^{*} \\
(-5.6754)\end{array}$ & -6.43070 & $\begin{array}{l}0.06229 \\
{[0.8029]}\end{array}$ \\
\hline
\end{tabular}

Notes: $* * * \& * * *$ - indicates the significance at one, five and ten percent level, respectively. ( ) $-\mathrm{z}$ values are in the parenthesis. [] - values in the squared brackets indicate probability value.

Table 6 shows the hybrid ARIMA-GARCH-M type models for the NSE returns. The AR and MA parameters in all the estimations are statistically significant. As the sum of ARCH $(\alpha)$ and GARCH $(\beta)$ effects in the ARIMA-GARCH-Mean estimations are close to one, the volatility clustering is evident in the NSE returns series during the pre-COVID, COVID pandemic outbreak and whole sample periods. Inconsistent with the BSE returns, the results exhibit long memory in the volatility during the study periods. According to AIC criteria and significant asymmetric parameters, the ARIMA-EGARCH-M models are more suitable than the ARIMA-GARCH$\mathrm{M}$ models. The significant asymmetric parameters $(\gamma \mathrm{s})$ suggests that the variance increases due to bad news than the good news during the sample periods. According to ARIMA-EGARCH-M models, the risk premium coefficients $(\lambda)$ are positive but statistically insignificant. This suggests no risk-return trade-off, implying that increased market risk does not necessarily imply higher market gains. Finally, we assessed whether the estimated hybrid ARIMAGARCH-M type models are free from the ARCH effect in the standardized residuals [29]. The insignificant ARCH-LM statistics reveal that the mean equations are well specified and free from heteroscedasticity.

\section{Conclusion}

According to descriptive statistics, the BSE and NSE return series is skewed, leptokurtic and nonnormal. Moreover, the stationarity conditions, autocorrelation and ARCH effects in the Indian stock market returns exhibit evidence contrary to weakform market efficiency. This confirms that investors can utilize historical returns to create strategies that outperform the market. Since the returns series exhibit strong ARCH effects, the estimation of hybrid ARIMA-GARCH-mean type models would be appropriate to model the volatility. It is also of great interest to evaluate the effectiveness of the symmetric GARCH specification with the asymmetric ones. Inconsistent with the substantial empirical literature to investigate market returns and volatility behaviour, we applied both hybrid symmetric GARCH and asymmetric GARCH models. It has been found that there is a positive risk-return association but not statistically significant during the sample periods. Thus, the CAPM portfolio theory is not postulated in the Indian stock markets. This is due to information asymmetry, and the long-memory process in the conditional variance plays a significant role in affecting the distribution of returns among investors. 
We found consistency in the findings across the sample periods on the volatility behaviour of the Indian stock markets. The study suggests that adverse shocks have a greater instantaneous effect on conditional volatility than positive shocks. In other words, short-term volatility and persistence of the variance process are primarily driven by negative shocks. The evidence against the weak-form efficiency and risk-return trade-off is due to long memory dynamics and asymmetric volatility during the sample periods. Thus, the regulators should enhance the informational efficiency of the Indian stock markets that results in a better understanding of the real sector and the effectiveness of the financial systems, as stock market prices precisely replicate companies' actual performance in the presence of market efficiency.

The presence of persistency and asymmetric dynamics of the variance process is evident. Thus capital market regulators should identify the causes of such volatility and timely disseminate the information to the investors. Furthermore, the regulators should review the circuit breaker system to control the volatility to ensure greater effectiveness and informational efficiency of the Indian Stock Exchanges.

The volatility of the Indian stock markets is more reactive to external shocks and sentiments and exhibits regime shift behaviour, characterized as bullish and bearish states. This leaves a larger scope for future research to comprehend the volatility dynamics using the Markov regime-switching-inmean and variance model. Furthermore, the study should consider the tick by tick data to capture recurrent regime switches in the Indian stock market returns.

\section{References}

[1]. Markowitz, H. M. (1968). Portfolio selection. Yale university press. https://doi.org/10.12987/9780300191677

[2]. Santa-Clara, P., Ghysels, E., \& Valkanov, R. I. (2004). There is a Risk-Return Tradeoff After All. NBER Working Paper, (w10913).

[3]. Green, T. C., \& Figlewski, S. (1999). Market risk and model risk for a financial institution writing options. The Journal of Finance, 54(4), 1465-1499. https://doi.org/10.1111/0022-1082.00152

[4]. Glosten, L. R., Jagannathan, R., \& Runkle, D. E. (1993). On the relation between the expected value and the volatility of the nominal excess return on stocks. The journal of finance, 48(5), 1779-1801. https://doi.org/10.1111/j.1540-6261.1993.tb05128.x

[5]. Mandelbrot, B. (1963). e variation of certain speculative prices, $\square$ e Journal of Business, 36 (4), 394-419. DOI: $h t t p: / / d x$. doi. org/10.1086/294632.
[6]. Engle, R. F., \& Bollerslev, T. (1986). Modelling the persistence of conditional variances. Econometric reviews, 5(1), 1-50.

https://doi.org/10.1080/07474938608800095

[7]. Black, F. (1976). Studies of stock market volatility changes. 1976 Proceedings of the American statistical association bisiness and economic statistics section.

[8]. Christie, A. A. (1982). The stochastic behavior of common stock variances: Value, leverage and interest rate effects. Journal of financial Economics, 10(4), 407-432.

https://doi.org/10.1016/0304-405X(82)90018-6

[9]. Aggarwal, R., Inclan, C., \& Leal, R. (1999). Volatility in emerging stock markets. Journal of financial and Quantitative Analysis, 34(1), 33-55.

DOI: https://doi.org/10.2307/2676245

[10]. Bekaert, G., \& Wu, G. (2000). Asymmetric volatility and risk in equity markets. The review of financial studies, 13(1), 1-42.

https://doi.org/10.1093/rfs/13.1.1

[11]. Bekaert, G., \& Harvey, C. R. (2002). Research in emerging markets finance: looking to the future. Emerging markets review, 3(4), 429-448. https://doi.org/10.1016/S1566-0141(02)00045-6

[12]. Bekaert, G., \& Harvey, C. R. (1997). Emerging equity market volatility. Journal of Financial economics, 43(1), 29-77.

https://doi.org/10.1016/S0304-405X(96)00889-6

[13]. Lim, C. M., \& Sek, S. K. (2013). Comparing the performances of GARCH-type models in capturing the stock market volatility in Malaysia. Procedia Economics and Finance, 5, 478-487. https://doi.org/10.1016/S2212- 5671(13)00056-7

[14]. Ugurlu, E., Thalassinos, E., \& Muratoglu, Y. (2014). Modeling volatility in the stock markets using GARCH models: European emerging economies and Turkey.

[15]. Gabriel, A. S. (2012). Evaluating the forecasting performance of GARCH models. Evidence from Romania. Procedia-Social and Behavioral Sciences, 62, 1006-1010. https://doi.org/10.1016/j.sbspro.2012.09.171

[16]. Coffie, W. (2015). Measuring volatility persistence and risk in Southern and East African stock markets. International Journal of Economics and Business Research, 9(1), 23-36.

[17]. Tripathy, T., \& Gil-Alana, L. A. (2015). Modelling time-varying volatility in the Indian stock returns: Some empirical evidence. Review of Development Finance, 5(2), 91-97.

[18]. Palamalai, S., \& Kalaivani, M. (2015). Day-of-theWeek Effects in the Indian stock market. Srinivasan, P. and Kalaivani, M.(2014), Day-of-the-Week Effects in the Indian Stock Market, International Journal of Economics and Management, 8(1), 158-177.

[19]. Vasudevan, R. D., \& Vetrivel, S. C. (2016). Forecasting stock market volatility using GARCH models: Evidence from the Indian stock market. Asian Journal of Research in Social Sciences and Humanities, 6(8), 1565-1574. DOI:10.5958/2249-7315.2016.00694.8 
[20]. Dangi, V. (2017). Volatility Clustering, Risk-Return Relationship and Leverage Effect in Indian Public Sector Banks' Returns. Ramanujan International Journal of Business and Research, 2, 153-165. https://doi.org/10.51245/rijbr.v2i1.2017.127

[21]. Mutaju, M., \& Pastory, D. (2019). Modeling stock market volatility using GARCH models case study of dar es salaam stock exchange (DSE). Review of Integrative Business and Economics Research, 9(2), 138-150.

[22]. Herbert, W. E., Ugwuanyi, G. O., \& Nwaocha, E. I. (2019). Volatility clustering, leverage effects and riskreturn trade-off in the Nigerian stock market. Journal of Finance and Economics, 7(1), 1-13. DOI:10.12691/jfe-7-1-1

[23]. Chaudhary, R., Bakhshi, P., \& Gupta, H. (2020). Volatility in international stock markets: An empirical study during COVID-19. Journal of Risk and Financial Management, 13(9), 208. https://doi.org/10.3390/jrfm13090208

[24]. Duttilo, P., Gattone, S. A., \& Di Battista, T. (2021). Volatility modeling: an overview of equity markets in the euro area during COVID-19 Pandemic. Mathematics, 9(11), 1212. https://doi.org/10.3390/math9111212
[25]. Yousef, I. (2020). Spillover of COVID-19: Impact on stock market volatility. International Journal of Psychosocial Rehabilitation, 24(6), 18069-18081. DOI: 10.37200/IJPR/V24I6/PR261476

[26]. Bora, D., \& Basistha, D. (2021). The outbreak of COVID-19 pandemic and its impact on stock market volatility: Evidence from a worst-affected economy. Journal of Public Affairs, 21(4), e2623. doi: 10.1002/pa.2623

[27]. Zhang, N., Wang, A., Haq, N. U., \& Nosheen, S. (2021). The impact of COVID-19 shocks on the volatility of stock markets in technologically advanced countries. Economic Research-Ekonomska Istraživanja, 1-26. https://doi.org/10.1080/1331677X.2021.1936112

[28]. Nitesha Dwarika, Peter Moores-Pitt and Retius Chifurira (2021). Volatility dynamics and the riskreturn relationship in South Africa: A GARCH approach. Investment Management and Financial Innovations, 18(2), 106-117. http://dx.doi.org/10.21511/imfi.18(2).2021.09

[29]. Enders, W. (2004). Applied econometric time series 2nd edition. New York: John Willey \& Sons. Technometrics, 46(2), 264-264. 